\title{
Discussion on Community Policing and Police-citizen Communication Ethics
}

\author{
Jun $\mathrm{Lu}$ \\ Teaching Department of Ideological and Political Theory \\ Sichuan Police College \\ Luzhou, China 646000
}

\begin{abstract}
The public service nature, the prevention and control of functions, and the basic nature of the region of community policing management determines that police officers should establish good public relations with the community. Good communication between the police and the citizens is the basis for building a harmonious relationship between the police and the people. It will be very important to improve the communication methods of the police and the citizens, pay attention to the communication ethics of the police and the citizens, thus establishing a harmonious community police-civilian relationship and promoting the construction and development of community policing.
\end{abstract}

\section{Keywords—community policing; communication; ethics}

\section{INTRODUCTION}

Community policing is a crime prevention strategy based on renovating the root causes as the main and the symptoms as the auxiliary. It emphasizes that police work should be based on the community, with social management service functions as the mainstay, close police-citizen relations, and work with the masses and various social organizations in the community to maintain law and order, prevent and combat crime. Community policing is based on the two-way communication and interaction between the police and the citizens. Without such communication and interaction, there is no community policing. Community policing should be based on the community and rely on the masses to become an open system of communication with the society. If there is a fault or isolation in the communication between the police and the citizens, it will affect the relationship between the police and the citizens in the community. When the relationship between the police and the citizens in the community is not harmonious, and the conflicts between the police and the citizens cannot be resolved in time, the construction of a harmonious relationship between the police and the citizens cannot be realized. The effective communication between the police and the citizens is essential when establishing a harmonious community policecivilian relationship. Ethics itself has the social function of coordinating interpersonal relationships, and thus can play a role as a lubricant in community police-citizen communication. The purpose of lubrication is to make the moral interaction between the police and the community more benign, and the interpersonal communication be smooth, so as to achieve harmony between the citizens and the police in the community, and promote the construction of community policing.

\section{ETHICAL LUBRICATION FACTORS IN COMMUNITY POLICING COMMUNICATION}

In the practice of police life in real life, the police and the citizens are often affected by the inappropriate communication methods, the obstructed communication channels and the subjective factors of the communication. As a result, some police work is inefficient, and there is some discord between the police and the citizens. Therefore, effective communication plays an important role in close police-citizen relations. However, in addition to the correct communication methods, skills and smooth communication channels, effective communication requires more ethical lubrication in communication. Communication as a form of association is also called moral communication. "Ethical communication is communication that is honest, satisfactory, and considering the rights of others." [1] Therefore, the police communicate with the community, in addition to mastering general communication skills, the most important thing is to consider the application of ethical factors in communication. Because communication is an interaction between people, it will inevitably be influenced by various subjective factors such as personality, temperament, attitude, emotion, opinion, and ideas. If the policemen do not consider the subjective factors of people, and do not pay attention to the application of ethical factors in communication, the communication will not achieve the expected result due to the lack of lubrication. Honesty, respect, equality and other ethical factors are effective lubricants in the communication between the police and the citizens. They play important roles in improving the relationship between the police and the citizens and promoting the construction of community policing.

Honesty is the basis of communication between the police and the citizens, which means that it should be used to make the communication smoother. Communication as a kind of discourse association, if the police and the citizens want to achieve effective discourse communication, they need to communicate "honestly" and "faithfully". According to Habermas's discourse ethics: A discourse needs to meet certain validity requirements in order to be understood by communicative actors and to complete a successful 
communication, that is, the requirements for the validity of the discourse. "These requirements include: 1 to say something understandable; 2 to provide (to the listener) something to understand; 3 to make himself understandable; 4 to reach a tacit agreement with another person." [2] In other words, effective communication must first satisfy the basic conditions of authenticity, equality, and cooperation. Honesty is also a basic social ethics. Honesty can gain the trust of the opposite party. The other party is willing to communicate with honest people. On the contrary, dishonesty can't gain the trust of the opposite party. The other party is therefore disgusted with you. As a result there will be communication barriers and the effective communication is not possible. For example, in the communication of community police practice, the information transmitted by the sender involves personal privacy and other aspects, and clearly indicates that it should not be disclosed to other people, and the recipient has received such information. At this time, the recipient should be sincere, honest and trustworthy, and promptly feedback the truthful and reliable information to the other party. However, the recipients who are not trustworthy will relish the information and even disclose the information to the public in violation of credit. The communication results can be imagined. In the next communication, the sender will take the lead, and the communication will not be smooth, and it will not achieve the expected effect.

Honesty asks the police to have an honest heart. The ancients said: "The sincerity can be seen in a person's appearance if he is sincere in his heart." Sincerity means that the police treat people with sincerity. The masses can feel the sincerity from the external expressions of the police's expressions and words. This feeling invisibly allows the masses to accept the police more quickly. When the police are sincere, the public's recognition of the police will make communication a good foundation. Only a sincere policeman can gain the trust of the masses and win the trust of the masses. It can produce the charisma that makes the masses happy to interact with the policeman. A policeman who treats each other with sincerity and is full of energy will easily motivate the people to communicate. Treating people with sincerity is a concrete manifestation of sincerity. If the police treat people with sincerity, they should protect the masses and treat the masses as friends. In communication, if the police regard the masses as friends, the communication will be a happy thing. Therefore, in the communication, the expression of the police is from the heart and sincerity. This sincere emotion will infect the masses, and the masses will also be sincere in returning each other. Such a virtuous circle will make the police and the masses have a good mood, the language of communication will be easy and pleasant, and the communication will be smooth and effective.

Honesty also requires the police to have a sincere attitude. Without a sincere attitude, the masses generally think that the police are inaccessible and thus keep the police away. The survey of social psychology proves that people are particularly interested in the sincerity, kindness and easygoing shown by strong people and capable people. They psychologically hope that he can communicate with themselves, otherwise they will feel far apart and have psychological barriers. [3] This way reduces the chances of frank communication between the police and the masses, and also makes effective communication unable to begin. Sincere attitude also provides a good atmosphere for communication. When the two sides try to establish two-way communication, they will find that there are great differences between them in some aspects. In communication, one wants to take the initiative, and he psychologically has the motivation to control and compete. Such motives will undoubtedly hinder effective communication, and sincere attitudes will reduce or eliminate these psychological reactions and provide a good atmosphere for communication.

The deeper connotation of communication is the psychological communication between people. People want to be treated equally by others, especially for the masses. The police must understand that he and the masses are equal in personality and must be treated equally. If the police have a superior feeling, they will easily become impatient. If the words are hard, the masses will have a psychological opposition to the police. The behavior of the masses will naturally show distance from the police and even confrontational behavior. Even they have words to say, they won't say it. So, where do the communications of the two sides start? Therefore, the police must be equal and maintain the same attitude towards the masses, so that the communication between the two sides will have fewer side effects, and the masses will not have negative emotions of confrontation and communication. Communicating with each other will not encounter resistance from the masses. Adhering to the blending of heart and heart, this is the highest level of equal communication. If the police exchange their true feelings with the true feelings, and they are intimate with the hearts of the people, they can consider the problem from the perspective of the other side, so that effective communication can be carried out.

Honesty is a guarantee of complete and true information transmission, and equality provides a platform for the police to exchange ideas with the masses. Moral equality is mainly about the equality of personality. It recognizes that people are the purpose, and everyone has a personal dignity. The ethical factor of equality is used in the communication between the police and the citizens to stimulate the creativity of the masses, eliminate the dissatisfaction of the masses, and remove the communication barriers between the police and the citizens. The expression of dissatisfaction of the masses is a concrete form of ideological communication. The dissatisfaction of the masses has many aspects, such as social security issues, community security conditions, and the strong language style of individual police officers. Once the dissatisfaction of the masses has accumulated, over time, it will affect the relationship between the police and the citizens. The police must pay attention to the dissatisfaction of the masses in the community work. Through equal communication, the masses vent their dissatisfaction, and the police discover weak links in community policing activities and take active measures to resolve these links. The masses must fully express their dissatisfaction and need to have an audience. These audiences are often the most trusted people 
by the people dissatisfied. As long as the people dissatisfied vent dissatisfaction in front of the police with honest moral quality, it means that the police have successfully obtained his trust, and positive thought communication can be carried out. "Communication starts from the heart". When the police have gained the trust of the masses, it is a good beginning for ideological communication. The police must also have feelings. They should put themselves in the position of the masses and stand on the same level as the masses to listen to his dissatisfaction. Such ideological communication will be smoother and more effective because of the platform provided by the ethical factor of equality.

Respect can make the communication parties have a psychological tendency to actively communicate before the communication, so that the communication between the police and the citizens can achieve good results. The police respect the human dignity, respect the human personality, and truly regard the masses as partners in the same boat. Then the other side of the communication will have a tendency to actively communicate with him, "He respects me, and I should respect him." This opens the door to the communication between the two sides.

Communication is to use language as a carrier of information. The police must fully express their respect for the dignity and rights of the masses in a good language. From the perspective of human care, people's desire for praise is a lasting and deep need of everyone. A relaxed and pleasant language is easy to resolve the contradictions between the two parties, and it can make people feel happy. Good language can close the psychological distance between the two parties, and improve the alienation or nervous interpersonal relationship. The police will not use good and pleasant language to express their sense of respect, which will often dampen the self-respect of the masses, thus undermine the satisfaction of the social and psychological needs of the masses. In this way, it will be certain that the masses do not want to communicate with such police. In people's communication, the attitude of treating others often determines the attitude of others towards back. Therefore, the police must respect the masses in order to gain the goodwill and respect of the masses. To respect the masses, the police must first treat every one of the people equally with a benevolent heart. Then the police must respect the interests of the masses. Respecting the interests of the masses is not the communication itself, but it is a necessary prerequisite for communication. By communicating, coordinating and handling the interests of the masses, the police will be much easier to communicate with the masses each time

In summary, ethical factors such as honesty, equality, and respect have played a role in improving interpersonal communication, breaking the psychological fortification of both sides of communication, and transmitting friendly signals, so that police-citizen communication in community policing is smoother and more productive.

\section{ETHICAL INTERACTION IN THE PROCESS OF COMMUNICATION BETWEEN COMMUNITY POLICE AND CITIZENS}

Honesty is the foundation of communication, respect is the bridge of communication, and equality provides a platform for communication. The ethical lubrication factors have effectively promoted and improved the communication between the police and the citizens, thus establishing a good basis for police-civil relations. The ethical factors penetrate into the process of communication between the police and the citizens, and also provide tangible good interpersonal relations and intangible ethical atmosphere for the moral interaction between the police and the masses. From the community policing police-citizen communication practice process analysis, there are mainly ethical interaction methods such as non-power influence interaction and trust interaction.

\section{A. The Interaction of Non-power Influences}

The police's good personal prestige and noble personality charm can easily bring a sense of intimacy and trust to the community, and encourage the people to be willing to be consistent with the police. This special personality attraction and influence is a kind of non-power influence. From the essence, it is a moral influence. This influence is natural and non-mandatory. It is the process by which the masses voluntarily accept the influence through subtle influences on the psychological basis of conviction. The harmony between the police and the masses and the smooth and effective communication between the police and the citizens depends to a large extent on the non-power influence of the police. To give full play to the influence of the police and the citizens in communication, the police must first have a high sense of responsibility for community policing, and secondly have a convincing spiritual strength. Spiritual strength comes from good personal qualities, which include positive attitudes and good morals. This kind of good character is that the police must be honest, integrity is honest, and consistent, and words must be done. Such a policeman can receive the inner recognition and sincere praise of the masses, so that the masses are also infected by the charisma of the police in their presence. However, good personal qualities alone cannot form the non-power influences of the police. These qualities must be combined with the ability to actively communicate with others to function. It is a process of understanding that the police communicate with the masses, take the initiative to care for the masses, learn to talk with the masses and mobilize the enthusiasm of the masses. Through this communication process, the police will bring out their own personality charm, and through the subtle influence and great inspiration of the masses, the masses will have the conviction of forging ahead, thus imitating the advanced values and moral consciousness of the police individual to lay a good ideological foundation for the joint work of community policing.

\section{B. Trust Interaction}

Trust is an affirmation of the value of human beings. This kind of affirmation is respect. In the practice of community policing communication, if the police recognize the 
subjectivity and creativity of the masses and affirm the enthusiasm of the masses for policing, then the masses, after being trusted by the police, can be motivated to assist in the community policing work, and take community policing as their responsibility. Especially when the trust given by the police is consistent with the individual's intentions, interests and hobbies, it is not a burden but a pleasure for the masses to interact with the police. Therefore, the police must give full trust to every citizen and establish a sense of trust in their psychology. This requires the police to do the following: First, the police need to express trust in language. The police must fully express their belief in, trust, and respect the meaning of the masses. Whether it is an individual conversation or a public audience, it must show full trust in the masses. Second, trust need to be reflected in community policing. The police show their trust in the masses in the community policing work, that is, they must sink, be grounded, and unite with the masses to form a good relationship between the police and the citizens. They must be good at listening to and accepting opinions from all sides of the masses, seeking truth from facts, and taking the mass line. As a mass, in the practice of communication between the police and the citizens, people must first respect the personality of the police, maintain the prestige of the police, and should not adopt a gloating attitude toward the police's mistakes at any time and place, and should not seize a point without any rest to devalue the police, or intentionally hurt the personality of the police.

\section{Being Considerate of the Police}

The police also have specific difficulties in community policing. The occupational pressure is higher than other social occupations. They are often in full working condition of "white plus black". Therefore, when the masses ask the police to solve the problem, they should stand in the police's perspective and think about the police. This is more conducive to communication between the two sides, which is conducive to eliminating differences and achieving the goal of mutual benefit. In the process of communication and interaction between the police and the people, the moral and emotional feelings of each other blend together, and the values collide with each other. After the interaction, the moral cognition of each other is improved, the values are integrated, and the relationship between them is in a benign and dynamic balance. In order to build a harmonious relationship between the police and the citizens, it has laid a good foundation and promoted the construction of community policing.

\section{CONCLUSION}

To make the community policing work be carried out in an orderly manner, it requires the support of the community. The smooth implementation of various police measures also requires the understanding of the community. Therefore, increasing the ethical lubrication factor in community policing communication and paying attention to the ethical interaction in the process of community police communication can effectively overcome the obstacles in the police-citizen communication of community policing, and the police-citizen ethical communication of community policing will also build a bridge between the police and the citizen to be conducive to achieving the consensus of the police and the community and achieving the goal of community policing.

\section{REFERENCES}

[1] (U.S) Saundra Hybels, Communicating Effectively [M] Li Yekun, trans. Beijing, Huaxia Publishing House, 2005: 19. (in Chinese)

[2] (German) Habermas, Communication and Social Evolution [M] Zhang Boshu, trans. Chongqing: Chongqing Publishing Group, 1999, 3. (in Chinese)

[3] Yu Yilei, The Role of Chat in Management Communication [ J] Human Resource Development of China, 2001, 10. (in Chinese) 